\title{
Erratum to: Performance Evaluation of Space-Time Block Codes Over Keyhole Weibull Fading Channels
}

\author{
Kostas Peppas · Andreas Maras
}

Published online: 31 October 2009

(C) Springer Science+Business Media, LLC. 2009

Erratum to: Wireless Pers Commun (2008) 46:385-395

DOI 10.1007/s11277-007-9441-6

In Eq. 20 of the original publication a factor $\frac{1}{\ln 2}$ has been accidentally omitted.

The online version of the original article can be found under doi:10.1007/s11277-007-9441-6.

K. Peppas $(\varangle) \cdot$ A. Maras

Department of Telecommunication Science and Technology, University of Peloponnese, Tripoli, Greece e-mail: peppas@telecom.ntua.gr
A. Maras
e-mail: amaras@uop.gr 